\title{
Knowledge accelerator by transversal competences and multivariate adaptive regression splines
}

\author{
Magdalena Graczyk-Kucharska ${ }^{1}$ - Ayse Özmen ${ }^{2}$ - Maciej Szafrański ${ }^{1}$. \\ Gerhard Wilhelm Weber ${ }^{1,3} \cdot$ Marek Golińśki $^{1}$ - Małgorzata Spychała ${ }^{1}$
}

Published online: 23 July 2019

(c) The Author(s) 2019

\begin{abstract}
Transversal competences constitute a set of the knowledge, skills, and attitudes required for various positions and in different professions. Such competences include: entrepreneurship, teamwork, creativity, and communicativeness; they are increasingly listed by employers in different countries as the key requirements in the labor market. The article presents the model of accelerating the process of acquiring transversal competences, developed based on the analysis of data collected in four countries of the European Union: Poland, Finland, Slovakia, and Slovenia. In the analysis, multivariate additive regression spline method was used, along with artificial neural networks, in order to create the best model describing the influence of different variables on the acceleration of acquiring transversal competences. Herewith, we demonstrated that by accelerating the acquisition of the transversal competence of entrepreneurship is influenced by the following factors: rank of the training method in the developed matrix, student numbers and the weighted average of the pace of acceleration regarding the acquisition of the remaining transversal competences, i.e., teamwork, communicativeness and creativity by the given student. The results validate our new method of the acceleration of acquiring transversal competences by students. Students may be from various higher education institutions in different countries. Developed results may be used in the course of education within the framework of the already planned vocational courses and for developing the skills required by employers for various positions and in different professions.
\end{abstract}

Keywords Transversal competences · Modelling · Data mining · MARS · Competence management $\cdot$ Optimization

\agdalena Graczyk-Kucharska

magdalena.graczyk-kucharska@put.poznan.pl

1 Faculty of Engineering Management, Poznan University of Technology, ul. Strzelecka 11, 60-965 Poznan, Poland

2 Mathematics and Statistics, University of Calgary, 2500 University Drive, Calgary, AB, Canada

3 Institute of Applied Mathematics, Middle East Technical University, Ankara, Turkey 


\section{Introduction}

The contemporary labor market and knowledge-based economy pose great challenges for employees. One of such challenges is the "Fourth Revolution", brought about by the development of new technologies related to the Internet, the Internet of Things, Cloud Computing, Interpersonal Communication and Machines, including Cyber-Physical Systems (Lee et al. 2015). These can greatly impact the competitive status of enterprises on a global market. These have a high influence on the functioning of enterprises in any competitive market (Brettel et al. 2014; Graczyk-Kucharska et al. 2018), also in the area of Human Resources (Hellström et al. 2000; Kelly and Reimer 2017). Tenkasi and Boland (1996) believe that the role of information technology in knowledgeintensive companies is growing toward achieving mutual learning (Mohamed et al. 2006). The knowledge-management conceptual framework developed by Stankosky and Baldanza (2000) has considered technology equally as essential as learning, organization, and leadership (Mohamed et al. 2006). Tangible resources have a significant role in promoting companies' ability to perform. However, more crucial capabilities derive from the knowledge generated and collected by the company in form of a human capital, organisational routines, processes, procedures and normatives (Soosay and Hyland 2008).

Apart from tangible resources, among the factors competitive in the enterprise market, there are the non-tangible ones, including the knowledge and competences of the employees that the enterprise has in order to maximize profit and accelerate the accomplishment of the goals set by the enterprise (McClelland 1973; Woodruffe 1993; Whiddett and Hollyforde 2003; Spychała et al. 2017).

This is why in a knowledge-based economy it is requisite to accelerate the creation of knowledge resources in businesses (Szafranski 2015). The dynamic nature of competences, as well as the need to configure them properly, matching the specificity of the organisation (Kor and Mesko 2013), create the need to constantly improve and develop them in order to benefit from the resources of the knowledge (Wiig 1997) and skills of the enterprise. The future success, innovation and overall performance of enterprises depend on their ability to quickly adapt and integrate while remaining flexible and agile as well as on creating new organizational and managerial ties and relationships (Pártlová 2017). This is possible only if information about the knowledge and skills required by the enterprise is available (Bondar 2013).

Enterprises' requirements concerning to knowledge and competences' impose a professional approach on their development in the area of education (Hyland 1993) and on the application of implemented methods of accelerating their acquisition. The faster employees acquire knowledge and competences required to successfully deliver results at their workplace, and the sooner they get familiar with them, the more effectively they can perform.

Acceleration of reaching the goals is an example of business performance improvement, which can result in substantially increasing market strategic advantage. Therefore any means of accelerating the teaching, which translate directly into accelerating knowledge and competence creation in the company, inevitably leads to improvement of business operations (Szafrański 2015). 
The idea of accelerating knowledge and competences acquisition accompanies the activities carried out within the framework of the TKA (Technical Knowledge Accelerator $^{\circledR}$ ) initiative launched at Poznań University of Technology. The intention of the initiative was to take and carry out initiatives aimed at accelerating the creation of technical and mathematical-scientific knowledge resources within the society in order to accelerate the development of the knowledge-based economy in the Greater Poland region. This would also correspond to the principles described in the European Union's strategic documents and the guidelines concerning support for specific activities in the Greater Poland region. Some of the most important competences that are needed on the labor market are transversal competences such as: entrepreneurship, communicativeness, teamwork and creativity. These transversal competences are crucial in different branches among EU countries and it is important to improve and accelerate the development of these competences among graduates in a practical training process.

This is why one of the areas of research within the framework of the TKA initiative was the international project entitled "The acceleration method of development of transversal competences in the students' practical training process” (ATC), carried out in cooperation with six higher education institutions and two business institutions from Poland, Finland, Slovakia, and Slovenia. Based on the core value (Tierney 1999, p. 35), which is knowledge acceleration, the objective of the project was defined. That objective is to develop and implement an innovative method for accelerating the development of transversal competences of students by improving the use of practical training.

As part of the project, five selected processes of accelerating the acquisition of transversal competences were compiled and tested at six higher education institutions in four EU countries. Each of the processes includes at least three methods of practical training selected with the use of principles compiled and characterized on the project's website and taking into consideration the hierarchy of the training methods developed using the expert method (Szafranski et al. 2017). The training method hierarchy matrix includes not only the importance index of the selected transversal competences, which are important to entrepreneurs in the four selected countries, but also the influence on the acceleration of acquiring the selected four transversal competences. In the method, the importance of the given methods and other factors influencing the training process (e.g., selection of the training method, method duration, age, place, number of group members) were assessed. The factors which may influence the pace of growth of the transversal competences, characterized further on in the article, were taken into consideration in the analysis carried out with MARS method.

The role of higher education is based on teaching knowledge and skills. Measuring the effects of educational programs on development of the economy (Srikanthan and Dalrymple 2004; Becket and Brookes 2008; Leung 2004; Cox et al. 2010; Yokhaneh and Baghoumian 2014) and the evaluation of professional competences (Tigelaar and van der Vleuten 2014) has become a field of intensive studies in the past few years. Attempts related to both the development of a competence model with the use of mathematical methods (Wiecek-Janka et al. 2016) and to increase the quality of training, among others through quality in the area of education, have already been made and described in various articles (Harvey and Knight 1996; Haworth and Conrad 1997; 
Bowden and Marton 1998; Tierney 1998; Srikanthan and Dalrymple 2002). Models of transversal competences, including entrepreneurship, were formulated in the literature and evolved initially in the context of its education, through the impact of entrepreneurship on learning processes, social entrepreneurship, and extensive models that take into account environmental and community factors and their impact on innovation and creating new value. Here we refer to Table 1.

Still, the quality of education and adjusting competence training to the needs of the labor market is necessary and important (Srikanthan and Dalrymple 2004), and, to date, no method of measuring the acceleration of competences required by the entrepreneurs in the labor market has been developed. Researchers are trying to develop a consensus in this matter through a cooperation involving academic teams rather than individuals working separately in parallel (Bowden and Marton 1998, pp. 252-253).

The aim of the article is to develop a mathematical model of accelerating the acquisition of a selected transversal competence, namely, entrepreneurship. An analysis of the influence and the interrelationships between the factors influencing the pace of acceleration of the acquisition of transversal competences will be used with the multivariate adaptive regression splines (MARS) method. It will make possible to identify significant factors influencing the acceleration regarding the growth of transversal competences.

In our study, this method is newly introduced by us in the context of the labor market and education, and we suggest two models based on MARS and the artificial neural network (ANN) as an existing method. MARS (Friedman 1991) is a form of non-parametric regression analysis. It has been applied in many fields of science, economics, finance, technology, medicine and control design in recent years. ANN methodology is also a nonparametric learning and nonlinear technique which is widely used in those areas.

\section{The importance of transversal competence in the new economy}

\subsection{The role of human resources and their competences}

Employee competences are defined as their skills, attitudes and knowledge, reflected in their conduct and resulting in the completion of tasks in their given position. This definition was developed in 1982 by Boyatzis, who emphasized that the employee's competences meet the requirements of the given position within the framework of the parameters of the organisation's environment, which in turn provides the desired results (Armstrong and Taylor 2014; Ashworth and Saxton 1990; Boyatzis 1982). Elements of competences may be an outcome, piece of knowledge, behaviour, understanding or an action (Eraut 1998).

From the perspective of a business, competences should be considered as tasks performed in a given position. An approach is used by Dale and Iles (1993), who underline that the competences required for the given activity are specified by the enterprise along with the specification of the level of the given skill. The authors claim that the most crucial elements of competences are "skills"-when the person "can" perform the task, it means that he/she has the right competences. This view is shared 
Table 1 Overview of selected models of entrepreneurship-literature formulation

\begin{tabular}{|c|c|c|c|}
\hline References & Article (short name) & $\begin{array}{l}\text { The approach to } \\
\text { entrepreneurship modelling }\end{array}$ & Mathematical model \\
\hline $\begin{array}{l}\text { Naman and Slevin } \\
\text { (1993) }\end{array}$ & A model and empirical tests & $\begin{array}{l}\text { Entrepreneurship and 'fit' in } \\
\text { small and medium sized } \\
\text { high technology } \\
\text { manufacturing firms }\end{array}$ & Yes \\
\hline Honig (2004) & $\begin{array}{l}\text { Model of contingency-based } \\
\text { business planning }\end{array}$ & $\begin{array}{l}\text { Pedagogical perspective and } \\
\text { business planning education }\end{array}$ & No \\
\hline Zahra et al. (2006) & $\begin{array}{l}\text { Entrepreneurship and } \\
\text { dynamic capabilities: a } \\
\text { review, model }\end{array}$ & $\begin{array}{l}\text { Dynamic capabilities and } \\
\text { their influence on the firm's } \\
\text { entrepreneurial and learning } \\
\text { process }\end{array}$ & Yes \\
\hline $\begin{array}{l}\text { Weerawardena } \\
\text { and Mort (2006) }\end{array}$ & A multidimensional model & Social entrepreneurship & No \\
\hline $\begin{array}{l}\text { Ireland et al. } \\
\quad(2003)\end{array}$ & $\begin{array}{l}\text { A model of strategic } \\
\text { entrepreneurship }\end{array}$ & $\begin{array}{l}\text { Strategic entrepreneurship for } \\
\text { company wealth creation }\end{array}$ & No \\
\hline $\begin{array}{l}\text { Salarzehi et al. } \\
\text { (2010) }\end{array}$ & $\begin{array}{l}\text { Social entrepreneurship } \\
\text { model in islam }\end{array}$ & $\begin{array}{l}\text { Social welfare as a specific } \\
\text { unique Islamic social } \\
\text { entrepreneurship }\end{array}$ & No \\
\hline Wood (2011) & $\begin{array}{l}\text { A process model of academic } \\
\text { entrepreneurship }\end{array}$ & $\begin{array}{l}\text { Multi-stage process model of } \\
\text { academic entrepreneurship }\end{array}$ & No \\
\hline Wang et al. (2012) & $\begin{array}{l}\text { A unified model of } \\
\text { entrepreneurship dynamics }\end{array}$ & $\begin{array}{l}\text { Entrepreneurship model } \\
\text { about business decision } \\
\text { making and interdependent } \\
\text { household }\end{array}$ & Yes \\
\hline Lindawati (2014) & $\begin{array}{l}\text { Entrepreneurship model in } \\
\text { empowering micro, small } \\
\text { and medium enterprise }\end{array}$ & $\begin{array}{l}\text { Entrepreneurial capability } \\
\text { through focusing on } \\
\text { collective entrepreneurship } \\
\text { by enhancing individual } \\
\text { entrepreneurship }\end{array}$ & Yes \\
\hline $\begin{array}{l}\text { Awang et al. } \\
\quad(2015)\end{array}$ & $\begin{array}{l}\text { Strategic entrepreneurship } \\
\text { model for economic } \\
\text { transformation }\end{array}$ & $\begin{array}{l}\text { Strategic entrepreneurship } \\
\text { model on input, output and } \\
\text { process }\end{array}$ & No \\
\hline $\begin{array}{l}\text { Morgan and Sisak } \\
\text { (2016) }\end{array}$ & $\begin{array}{l}\text { A model of entrepreneurship } \\
\text { and fear of failure }\end{array}$ & $\begin{array}{l}\text { Role of fear and failure in the } \\
\text { decision to become an } \\
\text { entrepreneur }\end{array}$ & Yes \\
\hline $\begin{array}{l}\text { Karimi and Walter } \\
\text { (2016) }\end{array}$ & $\begin{array}{l}\text { Disruptive business model } \\
\text { innovation adoption, and its } \\
\text { performance }\end{array}$ & $\begin{array}{l}\text { Corporate entrepreneurship } \\
\text { attributes affecting } \\
\text { innovation adaption of } \\
\text { disruptive model, and } \\
\text { performance impact on } \\
\text { model }\end{array}$ & Yes \\
\hline Meri (2016) & $\begin{array}{l}\text { Human resources } \\
\text { management of } \\
\text { entrepreneurship-a } \\
\text { practical model }\end{array}$ & $\begin{array}{l}\text { Relationships among HR, } \\
\text { chosen competences and } \\
\text { other variables }\end{array}$ & No \\
\hline
\end{tabular}


Table 1 continued

\begin{tabular}{|c|c|c|c|}
\hline References & Article (short name) & $\begin{array}{l}\text { The approach to } \\
\text { entrepreneurship modelling }\end{array}$ & Mathematical model \\
\hline $\begin{array}{l}\text { Miller and Le } \\
\text { Breton-Miller } \\
(2017)\end{array}$ & $\begin{array}{l}\text { A model of challenge-based } \\
\text { entrepreneurship }\end{array}$ & $\begin{array}{l}\text { Impact of negative personal } \\
\text { circumstances on equally } \\
\text { powerful role in training } \\
\text { future entrepreneurs }\end{array}$ & No \\
\hline $\begin{array}{l}\text { Mahfuz Ashraf } \\
\text { et al. (2019) }\end{array}$ & $\begin{array}{l}\text { Social business as an } \\
\text { entrepreneurship model in } \\
\text { emerging economy: } \\
\text { systematic review and case } \\
\text { study }\end{array}$ & $\begin{array}{l}\text { Scopes of adopting social } \\
\text { business model for chosen } \\
\text { entities in new economies }\end{array}$ & No \\
\hline Kordel (2018) & $\begin{array}{l}\text { Technology entrepreneurship: } \\
\text { multidimensional model }\end{array}$ & $\begin{array}{l}\text { Model of technology } \\
\text { entrepreneurship as social } \\
\text { and environmental process }\end{array}$ & No \\
\hline
\end{tabular}

by Louart (1995), who perceives competences as employees' professional capabilities, including knowledge, which are being used at a given work post or elsewhere in the enterprise.

Knowledge includes ideas related to sustainable development, skills involve the use of tools to evaluate the impact of decisions related to environmental, social and economic components, and attitudes reflect a commitment to make decisions with a perspective of long-term strategies in companies (Pérez González 2016).

From the students' point of view, competences are defined in literature as destined for a productive life of practical action. They will do things, make things, design things and organise things, mainly in the co-operation with other people. Students improve their competences by the practice of skills and the use of knowledge. Competences let students solve problems in a better way and take up new challenges in life and in co-operation with others in society (Ashworth and Saxton 1990).

Competence training may be based on two models of learning: searching for new knowledge, processes, and skills; and exploitation of the existing knowledge, processes, and skills in a form of refinement and incremental improvement (March 1991). In the case of the ATC project, focus was placed on studying the acceleration of the acquisition of selected transversal competences: entrepreneurship, teamwork, communicativeness, and creativity, which are all important to enterprises and always sought after in various positions in the labor market (Szafranski et al. 2017).

The required organizational competences are related to the knowledge created and accumulated inside the company through human capital and organizational routines, processes, practices and standards (Soosay and Hyland 2008; Rabeh et al. 2013).

A profound analysis of employees' competences and their development is indispensable because they are a foundation of enterprises' competitive advantage. This is particularly true for industrial branches facing so-called "hypercompetition" (D' Aveni 1994), which denotes a competitive situation, where the main factor of success is the ability to continuously develop new products or processes (Gutjahr et al. 2008). 
Kelly and Reimer (2017) draw attention to several key competences in the context of Industry 4.0 and the Internet of People. Among them, they distinguish: the leadership and leadership development implications for the organization, the rhythm and depth of change required for an organization to remain competitive, and the ecosystem of relationships required to navigate effectively within such organization (Kelly and Reimer 2017; Graczyk-Kucharska et al. 2018). Both these and professional competences, also qualifications, often do not meet the demand for competences among employers, which hinders their further development and, consequently, there is no proper transfer in the context of enterprises (Eraut 1998). Our results and proposed methodologies help to fulfil this gap and provide an opportunity to develop faster the transversal competences needed by entrepreneurs on the labor market.

\subsection{Transversal competences in the new economy}

The "new economy" may be defined very differently by various individuals, although all of them emphasize to some extent the role of information technology and the information sector of the economy (Neumark and Reed 2004). For displaced workers, educational retooling should aid the transition from the old economy (labor intensive) to the new economy (knowledge intensive) jobs (Abel and Gabe 2011; Kalleberg 2011; Moretti 2004; Rubin 2012). This change indicates a growing demand in the labor market for human resources not in worker positions, but the changing expectations in terms of jobs and the competences of creativity, entrepreneurship, teamwork, and communicativeness. In its current state, the concept of new economy underlying the rise of globalization also refers to international transparency, financial integration, and mobility of resources (labor force, capital, money, etc.) (Hacioglu and Dincer 2016). In literature, studies have been conducted to verify how the content (e.g., theoretical knowledge) and the social context (e.g., cooperation and collaboration) of work in the new economy attributes value differently to human capital and age when compared with the same evaluation performed in the old economy (Davis and Rubin 2016).

In his article, Leadbeater points to three powers changing the world in the direction of the knowledge economy. He lists: finance capitalism, knowledge capitalism, and social capitalism. Markets and communities, companies and social institutions, should be harnessed to the goal of advancing and spreading knowledge. The author points out that knowledge is the most precious resource and that people should organize society to maximize its creation and use (Leadbeater 1999). The development of key competences has been broadly recognized as an important imperative by most of EU Member States. Key competences were expressed in the European Reference Framework, which became inherited from developments of the OECD, UNESCO and Member States themselves (Pepper 2011). The European Reference Framework defined key competences as knowledge, skills and attitudes relevant to the context: communication in the native language, communication in foreign languages, mathematical skills and basic competences in science and technology, digital competence, ability to learn, social and civic competences, initiative and entrepreneurship capacity, and cultural awareness and expression. All the above emphasize critical thinking, cre- 
ativity, initiative, problem solving, risk evaluation, decision making and constructive management of emotions (Pepper 2011).

Transversal competences, usually referred to as generic skills or interdisciplinary competences, can be used in the implementation of diverse tasks in many thematic and social areas (European Parliament and of the Council of 18 December 2006/962/WE). The European Parliament names the following transversal competences: learning to learn; social and civic competences; sense of initiative and entrepreneurship; cultural awareness and expression. Technical competences are no longer sufficient to meet the requirements of contemporary labor market. Individuals must also develop transversal competences, which will help in shaping relations with the environment, an entrepreneurial attitude and the ability of creative problem solving. They offer value added in relation to employment and social cohesion (European pact for youth), which underlines the significance of lifelong learning and ability to change and adapt. The importance of these competences has been recognized due to their transversal character.

The following four transversal competences were selected from those proposed by the European Parliament: Entrepreneurship, Creativity, Communicativeness and Teamwork. A significant part of the transversal competences, including entrepreneurship, creativity, teamwork, and communicativeness, are competences in various positions at work used also to specify key competences in these positions, called reference models (Spychała et al. 2017; Graczyk-Kucharska et al. 2018).

Creative problem solving, implementation of new ideas, effective communication and knowledge sharing in teams, as there are further competences of the future (such as mathematical abilities). In order to generate them, one needs to first understand and be able to define them precisely (Szafranski et al. 2017).

\section{Methodology}

\subsection{Artificial neutral network (ANN)}

An artificial neural network (ANN) is a computing tool whose operating principle is modelled on the way the brain works (Tadusiewicz 1993). An ANN makes it possible to create complex non-linear models relatively easily, by "learning" from the presented examples (Fausett 1994).

The advantages of ANN includes the fact that they are able to cope with incomplete data, they do not require the knowledge of the task solution algorithm (automatic learning), they can generalize unknown cases, and are able to realize associative memory (Hertz et al. 1991).

Certain input variables (data) are entered into the neural networks, whereas the outputs are defined by output variables (solutions). That is why they can be used wherever conclusions are made about certain unknown information (e.g., the height at the given point) based on certain known information (e.g., location within a space defined as a pair of coordinates $x$ and $y$ ) (Fausett 1994). Neural networks make it possible to model randomly composed non-linear functions. The process of "learning" of the regression type of networks and most of the classification networks takes place with the use of 
the so-called algorithm with a "teacher", i.e., through repeatedly "showing" the source data to the network along with the correct response (Patterson 1996). The crucial element of an ANN system is the artificial neuron, which reflects the basic characteristics of a biological system:

- a certain number of input signals reach the neuron,

- the signal value is introduced into the neuron through a connection of a certain weight,

- a threshold value activating the neuron is determined for the given neuron,

- the total excitation of the neuron is transformed into the layers making up the ANN.

Individual neurons are grouped into layers forming the ANN. The input layer makes it possible to enter source data into the network, the so-called hidden layers are used to process it, and the output layer makes it possible to pull the results out of the network. On the artificial neuron model, we apply the input vector $\boldsymbol{x}$ (i.e., the variables $x_{1}, \ldots$, $x_{\mathrm{n}}$ ) and after its processing we get the $y$ value at the output. The basic elements of the neuron are the values of weights $w$, the internal processing function and the activation function. The value of the output signal from the neuron is calculated in two stages (Stęgowski 2004).

At the first stage, input $x$ signals are multiplied by the corresponding weights $w$ and subjected to a given function. This stage is called the internal processing function; in practice, it is usually the summing function (the scalar product of the vector $\boldsymbol{x}$ and $\boldsymbol{W})$. At the second stage, the result of the internal $e$ processing function is subject to the action of a specific input-output function, called in this case as the $j$ activation function. Ultimately, for a single neuron, the $y$ output signal is calculated from the following relationship:

$$
y=\varphi\left(\sum_{i=1}^{n} w_{i} x_{i}\right)=\varphi(\boldsymbol{W} \cdot \boldsymbol{x})
$$

where $\boldsymbol{x}$, input data vector; $\boldsymbol{W}$, weight vector; $\varphi$, activation function; $y$, output signal.

Due to the topology, multilayer networks are commonly used in practice. In such a network, we distinguish between input layer, hidden layers and output layer. Connections between layers may have a different structure, but usually they are complete connections, which means that each neuron of a given layer is connected to all neurons of the layer following it. In this type of network, the signal flow is unidirectional. Mathematically, regarded the function realized by such a network can be written as:

$$
\boldsymbol{y}=\varphi_{w y}\left(\boldsymbol{W}_{w y} \cdot \varphi_{u k r}\left[\boldsymbol{W}_{u k r} \cdot \varphi_{w s}\left(\boldsymbol{W}_{w s} \cdot \boldsymbol{x}\right)\right]\right)
$$

where $\boldsymbol{x}$, input data vector; $\boldsymbol{W}$, weight matrix for the appropriate layer; $\varphi$, activation function for the appropriate layer; $\boldsymbol{y}$, output data vector.

The purpose of such a network is to implement a specific function, i.e., to obtain the desired response with given input values. This goal is achieved through the network learning process, i.e., the appropriate change in the value of neuron weights (Steggowski 2004). 
The manner of building structural connections between the layers of the network poses a significant problem. There are many types of neural networks, differing in terms of their structure and the operating principles. The most frequently used regression networks include the so-called multilayer perceptrons (MLP) and radial basis functions (RBF), as well as generalized regression neural networks (GRNN). In the case of GRNN, the teaching cases are copied to the neurons of the network's hidden layer.

\subsection{Multivariate adaptive regression spline}

The flexible regression methodology of multivariate adaptive regression spline (MARS) (Friedman 1991) modifies and involves a strategy of recursive partitioning to simplify higher-dimensional nonparametric programs. It does not need any special assumption on basic functional connections among both dependent and independent variables. MARS establishes a multivariate additive model in a two-stage process: the forward and backward stage (Hastie et al. 2001).

In MARS' forward stage, it explores principal functions (BFs) that ought to be inserted into the model through a very quick search algorithm, and it builds up a big model that usually "overfits" the given data. This process stops as soon as the model has achieved a certain maximum number of BFs, $M_{\max }$, preassigned through the MARS user.

In MARS' backward stage, that overfit model becomes collapsed to some extent, herewith reducing the complexity of the model while fostering the overall achievement by addressing the fit into the dataset. On this stage, those BFs that cause the slightest growth of residual squared error are eliminated from the model and, at the end, an optimally estimated model has been established (Hastie et al. 2001; Özmen et al. 2014).

For MARS, we prefer the following denotation regarding its 1-dimensional piecewise linear BFs:

$$
c^{+}(x, \tau)=[+(x-\tau)]_{+}, \quad c^{-}(x, \tau)=[-(x-\tau)]_{+},
$$

with $[q]_{+}:=\max \{0, q\}$ and $\tau$ being a univariate $\operatorname{knot}(x, \tau \in \mathbb{R})$. Any one of these functions is piecewise linear with a knot $\tau$, and both mappings together are named as a reflected pair. Let us set up the subsequent general model about the relation between the input variables and the response variable:

$$
Y=f(\boldsymbol{X})+\varepsilon,
$$

where $Y$ is the output or response, the vector $X=\left(X_{1}, X_{2}, \ldots, X_{p}\right)^{T}$ consists of the predictor variables, and $\varepsilon$ is an additional stochastic component supposed to have 0 mean and a finite variance. The goal is to define reflected pairs for all inputs $X_{j}(j=$ $1,2, \ldots, p)$ with $p$-dimensional knots $\boldsymbol{\tau}_{i}=\left(\tau_{i, 1}, \tau_{i, 2}, \ldots, \tau_{i, p}\right)^{T}$ at, or rather close to, the vectors of input data $\tilde{\boldsymbol{x}}_{i}=\left(\tilde{x}_{i, 1}, \tilde{x}_{i, 2}, \ldots, \tilde{x}_{i, p}\right)^{T}(i=1,2, \ldots, N)$ (see Hastie 
et al. 2001; Özmen and Weber 2014). In fact, the purpose is to develop a set of reflected pairs with respect to all the inputs $X_{j}(j=1,2, \ldots, p)$ :

$$
S:=\left\{\left[X_{j}-\tau\right]_{+},\left[\tau-X_{j}\right]_{+} \mid \tau \in\left\{x_{1, j}, x_{2, j}, \ldots, x_{N, j}\right\}, j \in\{1,2, \ldots, p\}\right\} .
$$

We can represent $f(\boldsymbol{X})$ as a linear combination, successively built up based on the set $S$ and including the intercept $\beta_{0}$, such that (4) takes the form:

$$
Y=\beta_{0}+\sum_{m=1}^{M} \beta_{m} T_{m}\left(\boldsymbol{X}^{m}\right)+\varepsilon .
$$

Actually, any $T_{m}$ stands for a BF or products of 2 or more such elements given in (5), and it is assessed from a set of $M$ many linearly independent BFs; $\boldsymbol{X}^{m}$ is a part (or: sub-vector) of $\boldsymbol{X}$ which contributes to the mapping $T_{m}$. Furthermore, all the $\beta_{m}$ are an unknown coefficient for an $m$ th BF or of the constant map 1 (here, $m=0$ ). Building the product of an existing BF with a truncated (piecewise linear) mapping implying a further variable, then, the existing BFs and the newly generated interaction BFs as well, are included into the approximation through MARS (Friedman 1991). Given that the input values differ from each other, there are $2 N p$ BFs looking as follows:

$$
T_{m}\left(\boldsymbol{x}_{i}^{m}\right):=\prod_{k=1}^{K_{m}}\left[s_{\kappa_{j}^{m}} \cdot\left(x_{i \kappa_{j}^{m}}-\tau_{\kappa_{j}^{m}}\right)\right]_{+} \quad(i=1,2, \ldots, N) .
$$

Here, $K_{m}$ means the number of truncated mappings, multiplied within the $m$ th BF, $x_{i \kappa_{j}^{m}}$ is the input variable that corresponds with the $k$ th truncated linear mapping within the $m$ th BF, $\tau_{\kappa_{j}^{m}}$ is the knot associated with $x_{i \kappa_{j}^{m}}$, and $s_{\kappa_{j}^{m}}$ denotes a selected sign \pm 1 (Hastie et al. 2001; Özmen et al. 2014).

In order to attain the model, a MARS forward stepwise code emanates from the constant map $T_{0}\left(\boldsymbol{X}^{0}\right)=1$ to assess $\beta_{0}$; all mappings in the pool of $S$ are candidates. At every stage, with 1 reflected pair from the BFs' set $S$, all product-valued functions $T_{m}\left(\boldsymbol{X}^{m}\right)$ inside of our model set are regarded as a new mapping pair and as joining the model set.

The model built at the forward stage typically overfits the dataset; therefore, a backward-pruning code is applied where the BFs contributing least to the model fit are progressively taken off. This iterative algorithm goes on until an optimal number of effective terms is reached within the terminal model. The sequence of models induced through this process is determined by the help of generalized cross-validation (GCV); the model with the best predictive fit is then selected. Herewith, at the end of this process, an assessed best model $f_{\mu}$ of each number of terms, $\mu$, is attained. For the MARS model, generalized cross-validation is used to find the optimal term number, $\mu$, also reflecting the lack of fit (LOF). The GCV criterion introduced by Friedman (1991) is of the form:

$$
\operatorname{LOF}\left(\hat{f}_{\mu}\right)=\operatorname{GCV}(\mu):=\frac{\sum_{i=1}^{N}\left(y_{i}-\hat{f}_{\mu}\left(\boldsymbol{x}_{i}\right)\right)^{2}}{(1-M(\mu) / N)^{2}},
$$


with $M(\mu)$ denoting the effective number of model parameters, and $N$ as the number of data.

\section{Our models}

\subsection{Collection of data}

Based on the data collected within the ATC project, the final models using MARS method have been developed step by step, which allow, among others, to identify the factors that have a significant impact on the acceleration of the acquisition of transversal competences. For a comparison, we also use ANN. We choose this method as supportive to our explanations and discussions, because ANN is a more model-free approach, differently from the more model-based approach of MARS. Our investigation shows that by comparing the two chosen important tools, which have paradigmatically different approaches (MARS as a model-based approach, and ANN as a model-free one), the model-based approach can be very successful.

In our MARS methodology, we have a rich choice: we can choose as we want we are not forced, we can control basis functions and, eventually, input variables are allowed and, in fact, how many such variables interact and where they do within the model. For the purpose of the analysis, data have been collected from testing five processes at six universities (Poznań University of Technology, Centria Ostrobotnia University of Applied Sciences, University of Maribor, University in Banska Bystrica, Wrocław University of Economics, Częstochowa University of Technology) from four European Union countries (Poland, Finland, Slovakia and Slovenia). The method is understood as a chain of activities, in which practical education methods are used to improve students' transversal competences. Research conducted under the ATC project assumes that there are at least three methods of practical education within the process.

The test on accelerating the acquisition of transversal competences was conducted on a relatively small sample of 113 students using a total of 10 different methods of practical education of students tested from February to October 2017.

Prior to the development and collection of data on the pace of acceleration of acquiring transversal students' competences, guidelines were defined in the ATC project as a basis for a harmonized way of data collection in the different countries. The methods chosen for particular processes were selected on the basis of a document approved by the partners, entitled "The development of principles for the selection of practical education methods for reference process models" (taking into account the developed matrix); a summary of the data collection method was also made in the form of consultations between the partners. The matrix of educational methods takes into account the research conducted in the 4 partner countries on the importance of transversal competences among employers $(N=135)$. The expert method (Szafranski et al. 2017) was used to evaluate each of the 85 educational methods by assessing the impact of a particular method on the growth of each of the analysed transversal competences, such as: entrepreneurship, teamwork, communication skills and creativity (cf. Table 2). 


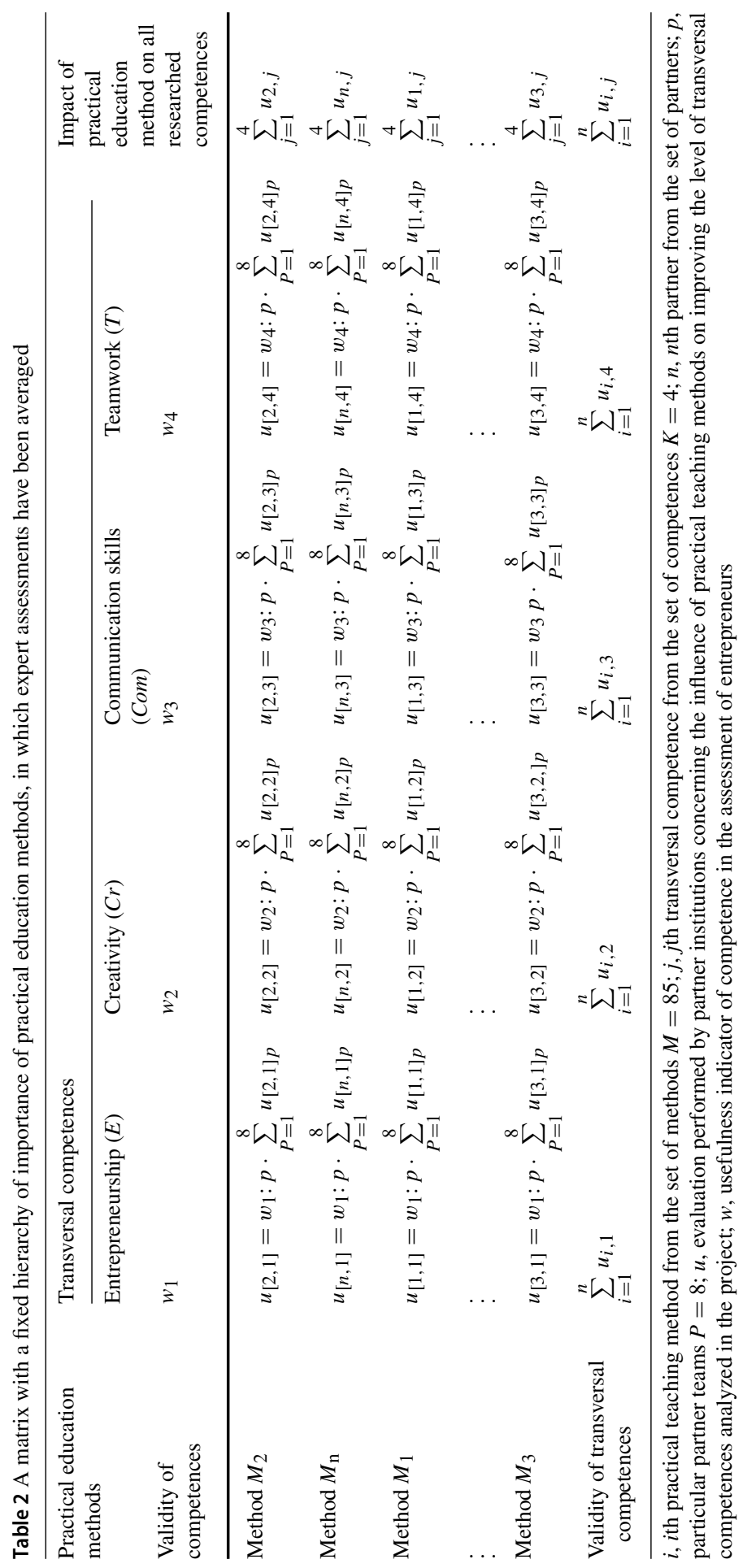


After determining the importance of the selected transversal competences for employers, determining the importance of educational methods for the growth of transversal competences and defining guidelines for the development of processes which are the basis for the study of the growth rate of transversal competences, the data on testing five processes at six universities in four EU countries were collected.

The study of the rate of change in the testing process under the ATC project was carried out using two methods: Audit Survey method and Indicator Analysis method (Szafranski et al. 2017). The first of these was presented in the MARS analysis.

All students participating as testers in the tested processes of practical education took part in the survey. The survey was conducted with their participation after applying each of the methods included in the process tested at a given university and in a given country. This also applies to a situation where the same methods were used at the same time. The students, on the basis of their self-assessment, determined the extent to which the level of their skills and, consequently, of the researched competences had increased after the application of each method. A six-stage scale from 0 to 5 was addressed in the study. It is assumed that in the case of transversal competences, the level of possessed skills, shaping the competence, cannot be reduced. The degree of change expresses the rate of change perceived by the students. After testing the process, in addition to the above data, information was also collected on the number of students per group, the year of study or the cultural factors that may influence the acceleration of the acquisition of the transversal competences in different EU countries. In this case, secondary data were used based on Hofstede factors (Hofstede 1984).

For modelling, in a first step, the analyses selected basic data for the development of a model for accelerating the acquisition of transversal competences. One of the transversal competences, i.e., entrepreneurship, was selected as the researched independent variable applied by MARS algorithm on $\mathbf{1 0 0}$ data considering the first 17 inputs (cf. Table 2). Then, to improve our model performance, we extended our data size and added time values as new inputs. So, we applied Neural Network and MARS on 339 data with regard to 26 inputs, as stated in Table 3.

In this application, to compare the performances of the prediction models obtained, we also applied the validation technique, where the dataset is divided into two subsamples as training and test sets. We used the NN and MARS algorithm on 270 data with regard to 26 inputs for training. 69 data were used for the test. The sample size was based on the chosen dateset for training and testing (random selection). We recall that, generally, the size of data for training is approximately $80 \%$ and the relative amount of data for testing is approximately $20 \%$.

\subsection{Developed model with the use of the neural network}

For a successful NN modeling, understanding certain model tuning parameters and selecting suitable parameter values are the key issues. So, the type of learning algorithm, the type of network, the number of hidden layers, the number of neurons in each layer and the type of activation function (transfer function) between layers should be decided correctly for the best network structure of NN. Nevertheless, the number of parameters to be tuned are large, there is no unique and explicit approach in order 
Table 3 Output and input variables used for developing MARS models

\begin{tabular}{llll}
\hline$Y$ & Average acceleration of entrepreneurship & $X_{14}$ & Masculinity (Hoffstede) \\
$X_{1}$ & No of students & $X_{15}$ & Uncertainty avoidance (Hoffstede) \\
$X_{2}$ & Rank of the method in the matrix & $X_{16}$ & Long-term orientation (Hoffstede) \\
$X_{3}$ & No of the method in the process & $X_{17}$ & Indulgence (Hoffstede) \\
$X_{4}$ & No of the process & $X_{18}$ & Timeline of the process \\
$X_{5}$ & Size of tested group & $X_{19}$ & Timeline of the method \\
$X_{6}$ & Number of meetings & $X_{20}$ & Start of the process \\
$X_{7}$ & Number of test groups & $X_{21}$ & End of the process \\
$X_{8}$ & Duration of testing (min) & $X_{22}$ & Starting time of the method \\
$X_{9}$ & Average acceleration of creativity & $X_{23}$ & Ending time of the method \\
$X_{10}$ & Average acceleration of communicativeness & $X_{24}$ & Cycle of the study \\
$X_{11}$ & Average acceleration of teamwork & $X_{25}$ & Year \\
$X_{12}$ & Power distance (Hoffstede) & $X_{26}$ & Semester \\
$X_{13}$ & Individualism (Hoffstede) & & \\
\hline
\end{tabular}

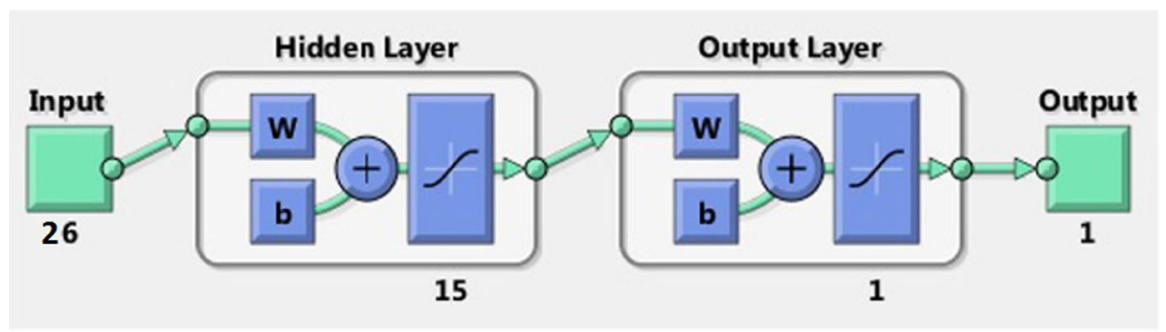

Fig. $1 \mathrm{NN}$ model for entrepreneurship forecasting

to choose these parameters, and these parameters highly rely on the type of specific application. Here, applicants usually prefer a basic trial-and error approach which increases the training time (Murata et al. 1994; Özmen et al. 2018).

In our study, the feed forward and multi-layered $\mathrm{NN}$ meta-models were trained through back-error-propagation (BEP) learning algorithm in order to provide an entrepreneurship prediction. For training the proposed NN model, we used MATLAB software (NNET toolbox). As seen in Fig. 1, we constructed an NN with 26 inputs in Table 2, 1 neuron in the output layer and 15 neurons in the hidden-layer for our model. Here, $w$ is represented as weight, $b$ is represented as bias and tansig function is employed as an activation function in the hidden-layer neurons.

\subsection{Developed model with the use of MARS}

For our MARS model, the optimally estimated models with the reduced number of BFs and a number of $M_{\max }$ BFs are obtained, after the forward and the backward step of MARS by its software (SPM 2018), by the help of generalized cross-validation (GCV) given in (8) and the optimal model with the best predictive fit is chosen. Here, 
the highest degree of interaction and $M_{\max }$ are assigned as 2 and 21 , respectively. Following the Backward Stage of MARS, the number of BFs is shortened to 11 . Consequently, the BFs in the backward stage are represented as follows:

$$
\begin{aligned}
B F_{1} & =\max \left\{0, x_{9}-3.66\right\}, \\
B F_{2} & =\max \left\{0,3.66-x_{9}\right\}, \\
B F_{3} & =\max \left\{0, x_{11}-0.14\right\}, \\
B F_{4} & =\max \left\{0, x_{1}-35\right\} \cdot \max \left\{0, x_{11}-0.14\right\}, \\
B F_{6} & =\max \left\{0, x_{2}-24\right\}, \\
B F_{8} & =\max \left\{0, x_{2}-24\right\} \cdot \max \left\{0, x_{11}-0.14\right\}, \\
B F_{9} & =\max \left\{0,24-x_{2}\right\} \cdot \max \left\{0, x_{11}-0.14\right\}, \\
B F_{10} & =\max \left\{0, x_{2}-19\right\} \cdot \max \left\{0,3.66-x_{9}\right\}, \\
B F_{14} & =\max \left\{0, x_{10}-0.25\right\}, \\
B F_{16} & =\max \left\{0,1.71-x_{11}\right\} \cdot \max \left\{0, x_{10}-0.25\right\}, \\
B F_{17} & =\max \left\{0, x_{11}-4.57\right\} \cdot \max \left\{0, x_{9}-3.66\right\}, \\
B F_{18} & =\max \left\{0,4.57-x_{11}\right\} \cdot \max \left\{0, x_{9}-3.66\right\}, \\
B F_{21} & =\max \left\{0, x_{1}-1\right\} \cdot \max \left\{0, x_{10}-0.25\right\} .
\end{aligned}
$$

The optimal MARS model with the BFs above is presented in the subsequent form:

$$
\begin{aligned}
\hat{Y} & =\beta_{0}+\sum_{m=1}^{M} \beta_{m} T_{m}\left(X^{m}\right)=\beta_{0}+\beta_{1} \max \left\{0,3.66-x_{9}\right\} \\
& +\beta_{2} \max \left\{0, x_{11}-0.14\right\}+\beta_{3} \max \left\{0, x_{1}-35\right\} \cdot \max \left\{0, x_{11}-0.14\right\} \\
& +\beta_{4} \max \left\{0, x_{2}-24\right\}+\beta_{5} \max \left\{0, x_{2}-24\right\} \cdot \max \left\{0, x_{11}-0.14\right\} \\
& +\beta_{6} \max \left\{0,24-x_{2}\right\} \cdot \max \left\{0, x_{11}-0.14\right\} \\
& +\beta_{7} \max \left\{0, x_{2}-19\right\} \cdot \max \left\{0,3.66-x_{9}\right\} \\
& +\beta_{8} \max \left\{0,1.71-x_{11}\right\} \cdot \max \left\{0, x_{10}-0.25\right\} \\
& +\beta_{9} \max \left\{0, x_{11}-4.57\right\} \cdot \max \left\{0, x_{9}-3.66\right\} \\
& +\beta_{10} \max \left\{0,4.57-x_{11}\right\} \cdot \max \left\{0, x_{9}-3.66\right\} \\
& +\beta_{11} \max \left\{0, x_{1}-1\right\} \cdot \max \left\{0, x_{10}-0.25\right\} .
\end{aligned}
$$

Random variables are congruent with the description in Table 3. For our MARS model, the number of students $\left(x_{1}\right)$, rank of the methods in the matrix $\left(x_{2}\right)$, average acceleration of creativity ( $\left.x_{9}\right)$, average acceleration of communicativeness $\left(x_{10}\right)$ and average acceleration of teamwork $\left(x_{11}\right)$ are significant. Here, all of the parameter values estimated for the MARS model are represented in Table 4. 
Table 4 Parameter values of the MARS model

\begin{tabular}{lccccc}
\hline$\beta_{0}$ & $\beta_{1}$ & $\beta_{2}$ & $\beta_{3}$ & $\beta_{4}$ & $\beta_{5}$ \\
\hline 2.064 & -0.554 & 0.284 & -0.005 & -0.008 & 0.021 \\
\hline$\beta_{6}$ & $\beta_{7}$ & $\beta_{8}$ & $\beta_{9}$ & $\beta_{10}$ & $\beta_{11}$ \\
\hline-0.004 & -0.0016 & 0.635 & 1.454 & 0.601 & -0.004 \\
\hline
\end{tabular}

\section{Comparison of the models}

\subsection{Performance criteria for comparison}

Statistical performance or comparison measures, stated in Table 5, have been applied to evaluate and compare the results of the proposed models. Here, our main performance measure is MAPE for its pronounced averaging property.

In any model, for AAE, RMSE and MAPE, smaller values closed to 0 give better results, whereas for $R_{a d j}^{2}$ and $r$ values closer to 1 are preferred.

\subsection{Results}

For intended entrepreneurship prediction, the NN and MARS models determined in the previous sections were evaluated based on the performance criteria by applying the formulas represented in Table 1. Table 5 shows the performance matrices for both the training and testing cases of NN and MARS models on entrepreneurship forecasting. In our study, we prefer the mathematical-statistical approach to performance criteria applied on our models. Herewith, we have at hand a well operational way to quantify uncertainty which exists in the given data and translates into our models, and we can rigorously compare the models. In future studies, "Soft" attributes and comparison measures can be used as well, to further simplify and "reduce" values of our goals to a few categories. In this paper, however, we pay special attention to the model goals of "accuracy" and "stability" which, in different ways, enter into our performance and comparison measures.

The training data have been gathered for 270 entrepreneurship values, and the test data have been provided for 69 entrepreneurship values. Based on the results in Table 6 , the MARS model achieved better results than the NN model for training. For the test data, MARS outperformed NN in all of the criteria. The performance gap of the test data is larger — too large - so that of the training data. As a result, the MARS model considerably outperforms the NN for the entrepreneurship prediction with respect to all measures. Moreover, MARS receives these results with only 5 inputs, whereas NN obtains an overfit model with the use of 26 input values. Consequently, in this particular problem, MARS should be the selected model and technique.

Based on NN and MARS, the predicted and observed entrepreneurship values, with additional plots showing the residuals, are also presented in Figs. 2 and 3. Furthermore, Average Absolute Errors (APEs) of the our considered models are demonstrated in Figs. 4 and 5 for the training and test data. 


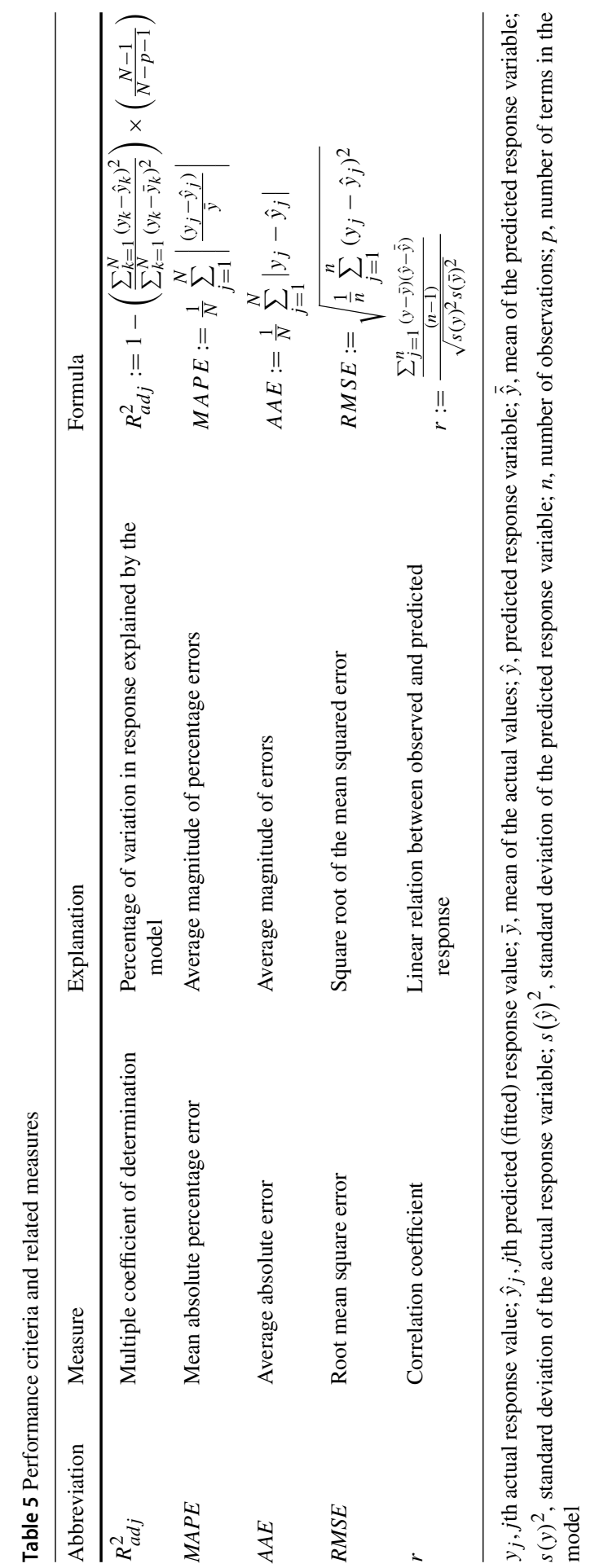


Table 6 Performance measures of NN and MARS models

\begin{tabular}{llllll}
\hline & \multicolumn{2}{l}{ Training } & & & \multicolumn{2}{l}{ Test } \\
\cline { 2 - 3 } \cline { 5 - 6 } & NN & MARS & & NN & MARS \\
\hline$R_{a d j}^{2}$ & 0.778 & 0.827 & & 0.216 & 0.766 \\
MAPE & 0.111 & 0.102 & & 0.281 & 0.157 \\
$A A E$ & 0.356 & 0.325 & & 0.799 & 0.447 \\
$R M S E$ & 0.492 & 0.434 & & 1.048 & 0.567 \\
$r$ & 0.89 & 0.914 & & 0.781 & 0.903 \\
\hline
\end{tabular}

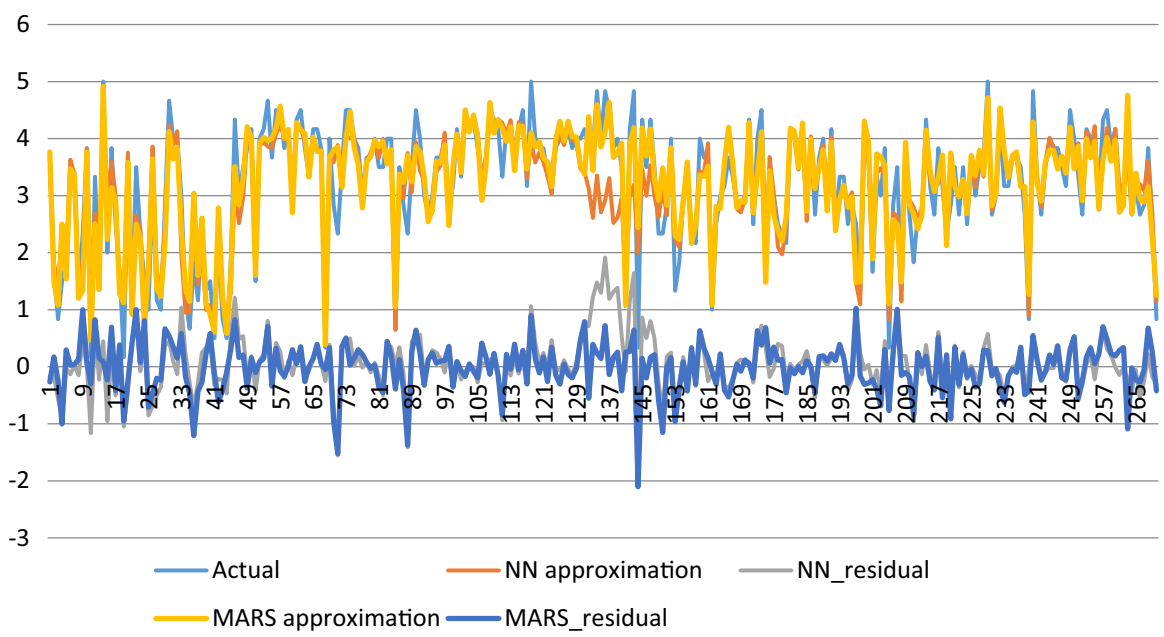

Fig. 2 Observed-predicted entrepreneurship values and residuals of NN and MARS models for the training data set

\section{Conclusions and outlook}

The issue of accelerating the acquisition of transversal competences among students and attempts at conducting statistical analyses concerning knowledge acceleration have not yet been broadly discussed in the literature. In cooperation with higher education institutions from Poland, Finland, Slovakia, and Slovenia, it was possible not only to develop a method of accelerating the acquisition of selected transversal competences, i.e., entrepreneurship, communicativeness, creativity, and teamwork, but also to analyze the data related to the development of the selected competences. This work resulted in the generation of models with the use of ANN and MARS.

During the analysis, one of the transversal competences, i.e., entrepreneurship, was selected as an independent variable. The results of the acceleration of the acquisition of this competence were analyzed with regard to the influence of dependent variables, i.e., data collected during the testing of the processes, and the selected transversal competences. A total of 26 variables were collected and analyzed among the data under analysis. They included the weighted average of the pace of acceleration of the creativity, communicativeness, and teamwork competences, the rank of the training 


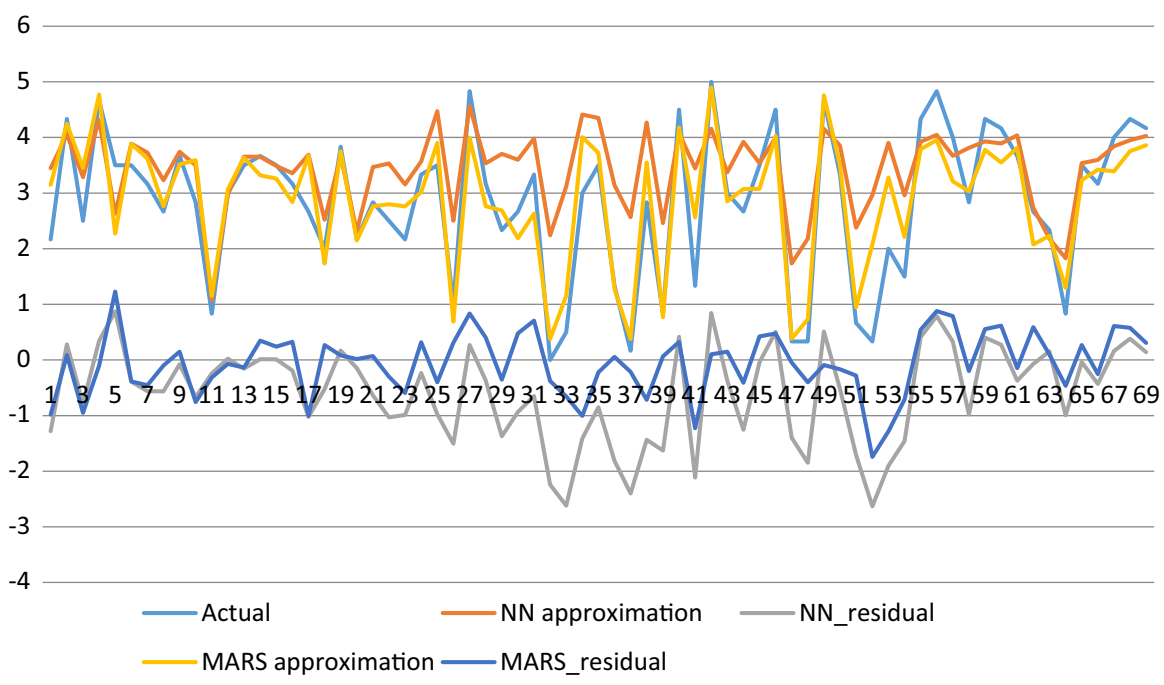

Fig. 3 Observed-predicted entrepreneurship values and residuals of NN and MARS models for the test data

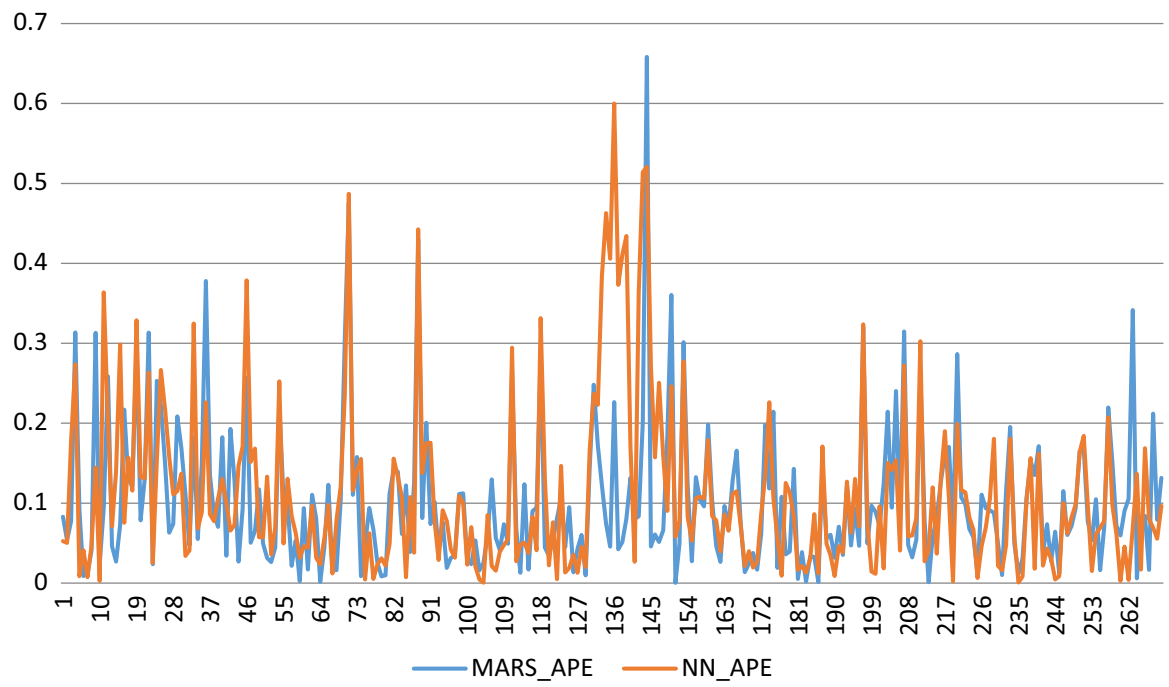

Fig. 4 Average absolute error (APE) of the NN and MARS models for the training data set

method in the matrix, size of the group, process duration, cultural factors (Hofstede 1984), and method duration.

The obtained study results have both a pragmatic and a theoretical dimension. The practical significance of the conducted research was demonstrated by implementing the developed method of accelerating the acquisition of transversal competences in five countries of the European Union and applying the way of selecting training methods influencing the acceleration of the competence acquisition among students. The theoretical dimension is revealed in the presentation of mathematical models confirming 


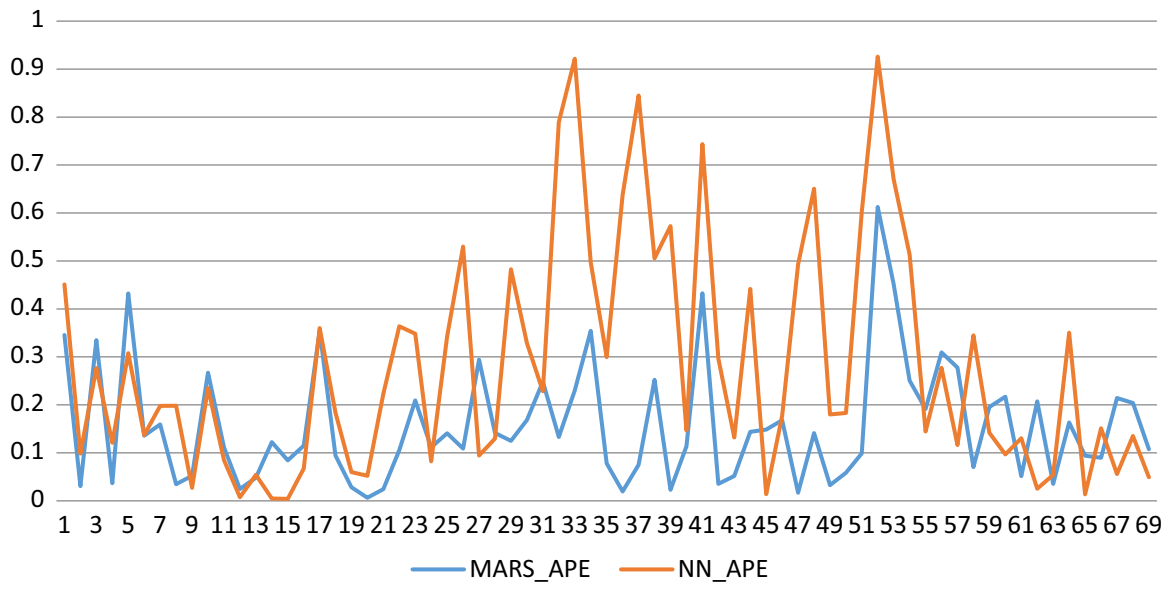

Fig. 5 Average absolute error (APE) of the NN and MARS models for the test data set

the validity of the conducted studies. By the MARS method we reconfirmed practical experiences about the significance versus insignificance of input variables (including the variable time also). Our MARS models are "handy" and allow discussions and interpretations, e.g., on the partial (marginal) influences of some input variables on the response variables, in terms of "sensitivities" given as functions of the other input variables.

Regarding the problem under study and after analyzing data on entrepreneurship using the ANN and MARS methods, in this particular case, MARS should be the selected model.

Based on NN and MARS, the predicted and observed entrepreneurship values, with additional plots showing the residuals, are also presented in Figs. 2 and 3. Moreover, Average Absolute Errors (APEs) of the our considered models are demonstrated in Figs. 4 and 5 for the training and test data. Our model is additive with multiplicative member functions. Through the multiplication in these entitled terms we have the opportunity to involve very rich forms of interaction. However, MARS provides also the opportunity to restrict the degree of interaction through a tuning parameter which is the upper limit of interaction.

In our study, we prefer the mathematical-statistical approach to performance criteria applied on our models. Herewith, we presented a well operational way to quantify uncertainty described in the given data and explain it by our models. We are able to rigorously compare models designed with ANN and MARS. In this paper, we pay special attention to the model goals of "accuracy" and "stability".

In the era of the knowledge-based economy, the significance of accelerating the acquisition of key competences required in the labor market is particularly high. Further work related to the acceleration of the acquisition of transversal competences should involve:

- increasing the scope of collected data by adding further EU countries, 
- expanding the data set of dependent variables by adding a set of data coming from secondary sources,

- applying different, new data analysis methods, e.g., CMARS (Özmen et al. 2014; Özmen 2016),

- analyzing other key competences required in the labor market, including professional competences.

In future studies, "Soft" attributes and comparison measures can be used as well, to further simplify and "reduce" values of our goals to a few categories. Furthermore, we also plan to conduct a simulation study on the influence of changes in educational and other policies towards a better fulfillment of the needs of modern labor markets and competitive economies. Moreover, we propose to apply robust MARS (RMARS) (Özmen and Weber 2014) and (robust) conic MARS ((R) CMARS) (Özmen et al. 2014; Özmen 2016) on data sets from modern labor markets and competitive economies to compare our models' performances in detail. Here, R(C)MARS will allow us to involve into our modeling uncertainty in the input variables, which is typical for realworld problems, too. In the future we will also use other performance criteria such as: Spearman's rank-order correlation or correlation coefficient.

Acknowledgements We would like to thank all of the Partners engaged fully in the project "The acceleration method of development of transversal competences in the students' practical training process" financed by EU funds under the Erasmus + Programme.

Open Access This article is distributed under the terms of the Creative Commons Attribution 4.0 International License (http://creativecommons.org/licenses/by/4.0/), which permits unrestricted use, distribution, and reproduction in any medium, provided you give appropriate credit to the original author(s) and the source, provide a link to the Creative Commons license, and indicate if changes were made.

\section{References}

Abel JR, Gabe TM (2011) Human capital and economic activity in urban America. Reg Stud 45(8):1079-1090

Armstrong M, Taylor S (2014) Armstrong's handbook of human resource management practice, 13th edn. Kogan Page, London

Ashworth PD, Saxton J (1990) On 'competence'. J Furth High Educ 14(2):3-25

Awang A, Kassim A, Noor AM, Shukor N, Shaari AZ, Amran S, Selmat SM, Khalid SA (2015) Strategic entrepreneurship model for economic transformation: Malaysian evidence. Asian Soc Sci 11(7):19

Becket N, Brookes M (2008) Quality management practice in higher education-what quality are we actually enhancing. J Hosp Leis Sport Tour Educ 7(1):40-54

Bondar AV (2013) The concept of the "new economy" and specifics of its development. Ekon Zarządzanie 5:7-18

Bowden J, Marton F (1998) The university of learning-beyond quality and competence in higher education. Kogan Page, London

Boyatzis RE (1982) The competent manager: a model for effective performance. Wiley, New York

Brettel M, Friederichsen N, Keller M, Rosenberg M (2014) How virtualization, decentralization and network building change the manufacturing landscape: an industry 4.0 perspective. Int J Mech Ind Sci Eng 8(1):37-44

Cox R, Gabris GT, Levin MM (2010) Educating local government managers for the twenty-first century: a preface to the symposium. J Public Aff Educ 16(3):325-336

D'Aveni RA (1994) Hypercompetition: managing the dynamics of strategic maneuvering. The Free Press, New York 
Dale M, Iles P (1993) Assessing management skills: a guide to competencies and evaluation techniques. Kogan Page, London

Davis DJ, Rubin BA (2016) Displacement in new economy labor markets: post-displacement wage loss in high tech versus low tech cities. Soc Sci Res 60:29-44. https://doi.org/10.1016/j.ssresearch.2016.04. 005

Eraut M (1998) Concepts of competence. J Interprof Care 12(2):127-139

European Economic and Social Committee and the Committee of the Regions (2006) Rethinking education: investing in skills for better socio-economic outcomes", 20 November 2012; key in the process of lifelong learning, OJ 394, 30 December 2006; education and training ("ET 2020”), OJ 119, 28 May 2009

Fausett LV (1994) Fundamentals of neural networks: architectures, algorithms, and applications, vol 3. Prentice-Hall, Englewood Cliffs

Friedman JH (1991) Multivariate adaptive regression splines. Ann Stat 19(1):1-67

Graczyk-Kucharska M, Szafranski M, Golinski M, Spychala M, Borsekova K (2018) Model of competency management in the network of production enterprises in industry 4.0 - assumptions. In: Hamrol A, Grabowska M, Maletic D, Woll R (eds) Advances in manufacturing. Springer, Cham, pp 195-204

Gutjahr WJ, Katzensteiner S, Reiter P, Stummer C, Denk M (2008) Competence-driven project portfolio selection, scheduling and staff assignment. CEJOR 16(3):281-306

Hacioglu U, Dincer H (2016) Concept of conflict within the new economy environment and its impact on the market mechanism. Int J Res Bus Soc Sci (2147-4478) 1(1):29-38

Harvey L, Knight PT (1996) Transforming higher education. Society for Research into Higher Education and Open University Press, Buckingham

Hastie T, Tibshirani R, Friedman JH (2001) The element of statistical learning. Springer, New York

Haworth JG, Conrad CF (1997) Emblems of quality in higher education. Allyn and Bacon, London

Hellström T, Kemlin P, Malmquist U (2000) Knowledge and competence management at Ericsson: decentralization and organizational fit. J Knowl Manag 4(2):99-110

Hertz J, Krogh A, Palmer RG, Horner H (1991) Introduction to the theory of neural computation. Phys Today 44:70

Hofstede G (1984) Cultural dimensions in management and planning. Asia Pac J Manag 1(2):81-99

Honig B (2004) Entrepreneurship education: toward a model of contingency-based business planning. Acad Manag Learn Educ 3(3):258-273

Hyland T (1993) Professional development and competence based education. Educ Stud 19(1):123-132

Ireland RD, Hitt MA, Sirmon DG (2003) A model of strategic entrepreneurship: the construct and its dimensions. J Manag 29:963

Kalleberg AL (2011) Good jobs, bad jobs. New York

Karimi J, Walter Z (2016) Corporate entrepreneurship, disruptive business model innovation adoption, and its performance: the case of the newspaper industry. Long Range Plan 49(3):342-360

Kelly S, Reimer D (2017) HR and the internet of people. People Strategy 40(3):6-7

Kor YY, Mesko A (2013) Dynamic managerial capabilities: configuration and orchestration of top executives' capabilities and the firm's dominant logic. Strateg Manag J 34(2):233-244

Kordel P (2018) Technology entrepreneurship: multidimensional model. Int Multidiscip Sci GeoConference SGEM Surv Geol Min Ecol Manag 18:815-821

Leadbeater C (1999) Towards the knowledge society (edited excerpt from book 'Living on Thin Air: The New Economy') (knowledge capitalism). New Statesman 128(4444):25(3)

Lee J, Behrad B, Kao HA (2015) A cyber-physical systems architecture for industry 4.0-based manufacturing systems. Manuf Lett 3:18-23

Leung SK (2004) Statistics to measure the knowledge-based economy: the case of Hong Kong, China. In: Asia Pacific Technical Meeting on Information and Communication Technology (ICT) Statistics, Wellington

Lindawati ASL (2014) A study of collective entrepreneurship model as an alternative in empowering Micro, Small and Medium Enterprise (MSME) cooperatives. J Econ Bus Account Ventura 17(2):171-186

Louart P (1995) Kierowanie personelem w przedsiębiorstwie. Poltext, Warszawa

Mahfuz Ashraf M, Razzaque MA, Liaw ST, Ray PK, Hasan MR (2019) Social business as an entrepreneurship model in emerging economy: systematic review and case study. Manag Decis 57(5):1145-1161

March JG (1991) Exploration and exploitation in organizational learning. Organ Sci 2(1):71-87

McClelland DC (1973) Testing for competency rather than for intelligence. Am Psychol 28:1-14 
Meri MM (2016) The decisive role of strategic human resources management in the success of entrepreneurship and innovation in the modern enterprise: a practical model. Zeszyty Naukowe Politechniki Poznańskiej. Organizacja i Zarządzanie, vol 68

Miller D, Le Breton-Miller I (2017) Underdog entrepreneurs: a model of challenge-based entrepreneurship. journals.sagepub.com

Mohamed M, Stankosky M, Murray A (2006) Knowledge management and information technology: can they work in perfect harmony? J Knowl Manag 10(3):103-116

Moretti E (2004) Workers' education, spillovers, and productivity: evidence from plant-level production functions. Am Econ Rev 94(3):656-690

Morgan J, Sisak D (2016) Aspiring to succeed: a model of entrepreneurship and fear of failure. J Bus Ventur 31(1):1-21

Murata N, Yoshizawa S, Amari S (1994) Network information criterion-determining the number of hidden units for an artificial neural network model. IEEE Trans Neural Netw 5:865-872

Naman JL, Slevin DP (1993) Entrepreneurship and the concept of fit: a model and empirical tests. Strateg Manag J 14:137-153

Neumark D, Reed D (2004) Employment relationships in the new economy. Labour Econ 11(1):1-31

Özmen A (2016) Robust optimization of spline models and complex regulatory networks: theory, methods and applications. Contributions to Management Science. Springer, Berlin

Özmen A, Weber G-W (2014) RMARS: robustification of multivariate adaptive regression spline under polyhedral uncertainty. J Comput Appl Math 259:914-924

Özmen A, Kropat E, Weber G-W (2014) Spline regression models for complex multi-modal regulatory networks. Optim Methods Softw 29(3):515-534

Özmen A, Yılmaz Y, Weber G-W (2018) Natural gas consumption forecast with MARS and CMARS models for residential users. Energy Econ 70:357-381

Pártlová P (2017) Indication of changes in projecting organizational structures under the new economy. Stud Commer Bratisl 10(38):175-187

Patterson DW (1996) Artificial neural networks - theory and applications. Prentice-Hall, Singapore

Pepper D (2011) Assessing key competences across the curriculum—and Europe. Eur J Educ 46(3):335-353

Pérez González JJ (2016) Social responsibility as a transversal competence of graduates. In: 6th international conference on changes in social and business environment: CISABE 2016, April 28-29, 2016, Panevežys, Lithuania, pp 45-49

Rabeh H, Jimenez-Jimenez D, Martínez-Costa M (2013) Managing knowledge for a successful competence exploration. J Knowl Manag 17(2):195-207

Rubin M (2012) Working-class students need more friends at university: a cautionary note for Australia's higher education equity initiative. Higher Educ Res Dev 31(3):431-433

Salarzehi H, Armesh H, Nikbin D (2010) Waqf as a social entrepreneurship model in Islam. Int J Bus Manag 5(7): 179

Salford Systems-Data Mining and Predictive Analytics Software (SPM) (2018) MARS software. http:// www.salfordsystems.com

Soosay C, Hyland P (2008) Exploration and exploitation: the interplay between knowledge and continuous innovation. Int J Technol Manag 42(1-2):20-35

Spychała M, Szafrański M, Graczyk-Kucharska M, Goliński M (2017) The method of designing reference models of workstations. In: European conference on knowledge management. Academic Conferences International Limited, pp 930-939

Srikanthan G, Dalrymple JF (2002) Developing a holistic model for quality in higher education. Qual Higher Educ 8(3):215-224

Srikanthan G, Dalrymple J (2004) A synthesis of a quality management model for education in universities. Int J Educ Manag 18(4):266-279

Stankosky MA, Baldanza C (2000) Knowledge management: an evolutionary Architecture Toward enterprise engineering. International Council on Systems Engineering (INCOSE), Reston, VA

Stęgowski Z (2004) Sztuczne sieci neuronowe. Wydawnictwa Naukowo-Techniczne, Kraków

Szafrański M (2015) Acceleration of educating as an external factor supporting preventive and improving actions in businesses. In: Ahram T, Karwowski W, Schmorrow D (eds) Procedia manufacturing, 6th international conference on applied human factors and ergonomics and the affiliated conferences, AHFE 2015, vol 3, pp 4948-4955

Szafranski M, Golinski M, Simi H (2017) The acceleration of development of transversal competences. Centria University of Applied Sciences, Kokkola 
Tadusiewicz R (1993) Sieci neuronowe [eng. Artificial neutral network]. Akademia Oficyna Wydawnicza, Warszawa

Tenkasi RV, Boland RJ Jr (1996) Exploring knowledge diversity in knowledge intensive firms: a new role for information systems. J Organ Change Manage 9(1):79-91

Tierney WG (1998) Responsive university: restructuring for high performance. Johns Hopkins University Press, Baltimore

Tierney WG (1999) Building a responsive campus: creating high performance colleges and universities. Sage Publications, Thousand Oaks

Tigelaar DE, van der Vleuten CP (2014) Assessment of professional competence. In: Billett S, Harteis $\mathrm{C}$, Gruber $\mathrm{H}$ (eds) International handbook of research in professional and practice-based learning. Springer, Dordrecht, pp 1237-1270

Wang C, Wang N, Yang J (2012) A unified model of entrepreneurship dynamics. J Financ Econ 106(1):1-23

Weerawardena J, Mort GS (2006) Investigating social entrepreneurship: a multidimensional model. J World Bus 41:21-35

Whiddett S, Hollyforde S (2003) A practical guide to competencies: how to enhance individual and organisational performance, CIPD, London, ISBN: 1-84398-012-6

Wiecek-Janka E, Mierzwiak R, Kijewska J (2016) Competencies' model in the succession process of family firms with the use of grey clustering analysis. J Grey Syst 28(2):121

Wiig KM (1997) Knowledge management: an introduction and perspective. J Knowl Manag 1(1):6-14

Wood MS (2011) A process model of academic entrepreneurship. Bus Horiz 54(2):153-161

Woodruffe C (1993) What is meant by a competency? Leadersh Organ Dev J 14(1):29-36

Yokhaneh M, Baghoumian R (2014) A study on the impact of the quality of management education on the new economy-knowledge: evidence from members of OIC countries. Manag Sci Lett 4(8): 1655-1660

Zahra SA, Sapienza HJ, Davidsson P (2006) Entrepreneurship and dynamic capabilities: a review, model and research agenda. J Manag Stud 43(4):0022-2380

Publisher's Note Springer Nature remains neutral with regard to jurisdictional claims in published maps and institutional affiliations. 